\title{
O Sistema Ético Skinneriano e Conseqüências para a Prática dos Analistas do Comportamento
}

\author{
Alexandre Dittrich ${ }^{2}$ \\ José Antônio Damásio Abib \\ Universidade Federal de São Carlos
}

\begin{abstract}
Resumo
Este artigo visa, a partir de uma análise crítica do sistema ético skinneriano, a apontar algumas das conseqüências deste sistema para a prática dos analistas do comportamento. Utiliza-se como fonte privilegiada de argumentação o próprio texto skinneriano e suas categorias conceituais. O texto delineia, inicialmente, a relação entre o sistema ético skinneriano e o modelo de seleção por conseqüências, analisando, em seguida, os aspectos descritivo e prescritivo daquele sistema. Por fim, as implicações dessas considerações para o exercício profissional da análise do comportamento são abordadas. Destaca-se o papel do analista enquanto agente político, e a necessidade de desenvolver práticas colaborativas para lidar com possíveis tensões entre o sistema ético do behaviorismo radical e os valores daqueles com quem o analista trabalha.

Palavras-chave: Behaviorismo radical; ética; seleção por conseqüências; análise do comportamento.
\end{abstract}

Skinner's Ethical System and Consequences for Behavior Analysts' Practice

\begin{abstract}
Starting with a critical analysis of Skinner's ethical system, this paper points to some consequences out of this system for the practice of behavior analysis. Skinner's writings and its conceptual categories are the main source of the arguments presented. Initially, the paper draws an outline of the relation between Skinner's ethical system and selection by consequences as a causal model, proceeding, then, to the analysis of both the descriptive and prescriptive aspects of that system. The paper finishes discussing the implications of these precedent considerations for the professional exercise of behavior analysis. This last part of the paper gives special attention to the role of the behavior analyst as a political agent, and to the need to develop collaborative practices in order to deal with possible tensions between the radical behaviorist ethical system and the values of the people with which the analyst works.

Keywords: Radical behaviorism; ethics; selection by consequences; behavior analysis.
\end{abstract}

A lógica do sistema ético skinneriano (Skinner, 1971) está intimamente ligada à do modelo de seleção do comportamento por conseqüências (Skinner, 1981/1984). De acordo com esse modelo, o comportamento humano só pode ser integralmente compreendido a partir da conjugação de variáveis atuantes em três diferentes níveis seletivos: filogenético (evolução das espécies), ontogenético (evolução de indivíduos particulares de uma espécie durante seu tempo de vida) e cultural (evolução das culturas). Isso inclui o comportamento ético, verbal e não-verbal.

Para Skinner, bens éticos são conseqüências do comportamento. Nos três níveis seletivos (filogenético, ontogenético e cultural) o comportamento produz certos efeitos, e é através destes efeitos que os problemas éticos devem ser analisados. O sistema ético skinneriano descreve três tipos de bens (1971). Bens pessoais são reforçadores positivos em relação ao comportamento da pessoa que os produz. Cabe destacar o

\footnotetext{
${ }^{1}$ Agradecimentos à FAPESP (Fundação de Amparo à Pesquisa do Estado de São Paulo), processo 02/02734-7.

${ }^{2}$ Endereço para correspondência:Rua Alferes Poli, 271, 1305, Curitiba, PR. Fone: (41) 30225179; Fax (41) 3102641.E-mail:aledittrich@ig.com.br

${ }^{3}$ Pesquisador do CNPq.
}

adjetivo positivos, pois reforçadores negativos são o oposto de bens pessoais (Skinner, 1971). Bens dos outros são aqueles que, ainda que produzidos por certo indivíduo, resultam em reforçamento positivo para o comportamento de outras pessoas que não o próprio indivíduo. Também estaremos agindo eticamente, nesse caso, ao remover reforçadores negativos em relação ao comportamento de outros. Bens das culturas são todas as conseqüências de práticas culturais que contribuem para a sobrevivência da cultura que promove tais práticas. O comportamento ético de qualquer ser humano define-se por sua relação com a produção desses três tipos de bens, que não é mutuamente exclusiva - isto é, uma pessoa pode, através de certa ação, produzir não apenas um, mas dois ou três tipos de bens simultaneamente.

Analisando conjuntamente o sistema ético skinneriano e o modelo de seleção por conseqüências, conclui-se que comportamentos eticamente bons são todos aqueles que "satisfazem" às contingências seletivas. Note-se que Skinner (1971) classifica como bens exatamente aquelas conseqüências que promovem a seleção do comportamento nos três níveis especificados. Entretanto, conforme veremos em seguida, não há perfeita simetria entre os três níveis que compõem, respectivamente, o modelo de seleção por conseqüências e 
o sistema ético skinneriano, dado que: 1) bens pessoais não incluem apenas reforçadores primários, mas também secundários; 2) bens dos outros são produzidos apenas sob circunstâncias especiais de seleção do comportamento operante no segundo nível. No primeiro nível, o comportamento é selecionado se contribui para a sobrevivência da espécie à qual pertence o indivíduo que se comporta. As conseqüências imediatas desse tipo de comportamento (alimento, sexo, segurança) adquirem, para certas espécies, propriedades reforçadoras. A estas conseqüências denominamos reforçadores primários, ou incondicionados, que são os principais bens pessoais, derivando destes reforçadores todos os demais bens pessoais - i.e., os reforçadores secundários, ou condicionados. No segundo nível, um operante é selecionado se produz reforço. As conseqüências reforçadoras que selecionam operantes - i.e., os bens pessoais - são, em sua ampla maioria, mediadas pelas pessoas com quem convivemos. Para que tenhamos acesso a tais conseqüências, temos que produzir bens para estas pessoas (os bens dos outros). Daí a explicação para o comportamento em benefício alheio: trata-se de reforçamento recíproco. Nas culturas humanas, a produção de bens para outros surge quase sempre como um pré-requisito para a obtenção de bens pessoais - e o próprio fato de que produzimos bens para outros só se justifica nesta medida. Finalmente, no terceiro nível, uma prática cultural é selecionada se contribui para a sobrevivência da cultura que a mantém. A conseqüência de práticas desse tipo é a própria perpetuação da cultura e das práticas que a compõem.

Entretanto, há que se notar o seguinte: não é Skinner quem está, a partir de julgamentos pessoais, qualificando esses comportamentos e suas conseqüências como bons. Ele está, em princípio, tão-somente descrevendo contingências naturais e culturais de seleção do comportamento por conseqüências. É evidente, no entanto, que essa descrição é realizada a partir de uma matriz teórica, e o conceito de descrição não alude, por conseguinte, a uma realidade "objetiva". Skinner não está ordenando, pedindo ou exortando para que trabalhemos por nossa sobrevivência biológica, ou para que busquemos produzir conseqüências reforçadoras para nós mesmos ou para outros, ou para que trabalhemos pelo futuro de nossas culturas. Isso tenderá a ocorrer a despeito da vontade de Skinner ou de qualquer outra pessoa. Há exceções, é claro, mas as contingências seletivas tendem a mantê-las em baixo número: espécies cujos membros não trabalhem por sua sobrevivência biológica tendem a extinguir-se, o mesmo ocorrendo com operantes que não produzam reforço e com culturas que não se ocupem de seu futuro. Assim, o que é "ético" tende a ser selecionado; o que é "antiético" tende a desaparecer. Porém, isso não leva, como pode parecer, ao domínio absoluto do "ético" sobre o "antiético". O princípio básico da seleção enquanto modelo de causalidade (a permanência do que é bom e o desaparecimento do que é ruim) constitui uma simplificação conveniente de processos extremamente complexos. A evolução jamais alcança uma estabilidade caracterizada pela permanência exclusiva do que é bom. O próprio conceito de seleção só se justifica em um quadro de referência constituído tanto por comportamentos bons quanto ruins - dado que, se todos os comportamentos fossem bons, todos seriam selecionados. Nesse caso, obviamente, o conceito perderia seu sentido. Além disso, um princípio amplamente aceito pelos teóricos da evolução filogenética encontra correspondência também nos demais níveis seletivos: os organismos, durante sua evolução, perseguem um "alvo móvel”; isto é: o que é bom hoje pode não sê-lo amanhã - e a própria mobilidade deste alvo é, em grande medida, determinada pelo comportamento do organismo que o persegue (Lewontin, 1998/2002,p. 63).

O terceiro nível seletivo, porém, assume posição de especial importância na filosofia moral skinneriana. Para compreendê-la, precisamos distinguir entre dois aspectos dessa filosofia.

\section{Sistema Ético Skinneriano: Aspectos Descritivo e Prescritivo}

Todos os detalhes da filosofia moral skinneriana que estudamos até o momento integram o que podemos chamar de seu aspecto descritivo. Trata-se de descrição no aspecto científico da palavra: para Skinner (1971), a ciência do comportamento é também ciência dos valores. Se valores estão nas contingências, valores são objeto de estudo da ciência. À parte tudo o que possamos pensar sobre questões éticas, a evolução das espécies, dos indivíduos e das culturas é um fato empírico. Assim, o aspecto descritivo do sistema ético skinneriano aplica-se ao estudo científico dos três níveis seletivos que controlam o comportamento ético. Ele possibilita elaborar uma ciência dos valores que explique: 1) porque seres humanos comportam-se eticamente; 2) porque seres humanos utilizam vocábulos de ordem ética; 3) porque seres humanos defendem/promovem certos valores éticos. Skinner está, portanto, meramente descrevendo, de maneira econômica, fenômenos naturais e culturais. Entretanto, para além desse aspecto descritivo, a filosofia moral skinneriana apresenta também um aspecto prescritivo. Esclareça-se, porém, que essa classificação - isto é, aspecto descritivo versus aspecto prescritivo - não ocorre no texto skinneriano.

Simplificadamente, um discurso descritivo é aquele que diz: "X é assim"; um discurso prescritivo, por outro lado, é aquele que diz: "X deveria ser assim". De acordo com o vocabulário tradicional da filosofia, dir-se-ia que essa é a diferença entre fatos e valores - ou, na teoria do comportamento verbal de Skinner (1957), entre tactos e mandos. Em seu aspecto descritivo, a filosofia ética skinneriana apresenta descrições do comportamento ético e das variáveis que o controlam. Assim, quando Skinner diz que as pessoas tendem a fazer aquilo que produz reforço para seu comportamento (ou seja, a produzir bens pessoais), ele está 
sendo descritivo - e, da mesma forma, está sendo descritivo quando diz que as pessoas trabalham para o bem dos outros desde que sejam reforçadas ao fazê-lo, ou quando diz que as práticas culturais que contribuem para a sobrevivência de uma cultura tendem a sobreviver junto com a cultura que as promove. Entretanto, dentre os três valores que descreve, Skinner elege um deles como o valor fundamental de sua filosofia moral: trata-se da sobrevivência das culturas (1953/ 1965, 1971). Para Skinner, todos os demais valores (bens pessoais e bens dos outros) devem estar subordinados a esse valor fundamental. Ora, quando Skinner elege tal valor, ele não está, certamente, realizando uma descrição: está, isto sim, emitindo o tipo de comportamento verbal que chama de mando - isto é, um comportamento que ordena, pede ou exorta (Skinner, 1957). Em outras palavras, Skinner está buscando modificar o comportamento de seus leitores numa direção que considera eticamente correta.

Pelo próprio fato de integrar o aspecto prescritivo da filosofia moral skinneriana, a sobrevivência das culturas não constitui um valor absoluto, "verdadeiro". Ela pode ser questionada, e não exime os behavioristas radicais de tomar parte no debate ético. É preciso deixar claro - por uma questão lógica - que a sobrevivência das culturas, enquanto valor (isto é, enquanto mando), não é uma decorrência necessária nem do modelo de seleção por conseqüências, nem da ciência dos valores que se apóia neste modelo. É perfeitamente possível ser um behaviorista radical e adotar como valor fundamental, por exemplo, a riqueza, a felicidade ou o prazer. Todos os que se identificam com o behaviorismo radical podem, legitimamente, perguntar: devemos adotar a sobrevivência das culturas como o principal valor de nossa ética? Valerá a pena defender tal valor ou devemos, por outro lado, buscar uma nova ética que norteie nossa atuação? Supondo que escolhamos a sobrevivência das culturas como valor ético fundamental, ainda assim é preciso notar que nossa ética é apenas mais uma dentre tantas outras - e, como tal, também exige justificação e defesa.

Em alguns momentos, porém, Skinner parece querer eximirse do debate ético, dando a entender que a sobrevivência das culturas - por ser um valor "natural" - goza de alguma espécie de preeminência sobre os valores de outros sistemas éticos. Sendo delineado a partir de uma perspectiva selecionista sobre as espécies, os indivíduos e as culturas, o sistema ético skinneriano busca legitimar todas as suas sentenças - tanto descritivas quanto prescritivas - apoiado nessa perspectiva. O modelo de seleção por conseqüências pode, perfeitamente, levar-nos a concluir que "a sobrevivência não é um critério o qual nós sejamos livres para aceitar ou rejeitar ...” (Skinner, 1955/1972a, p. 22), e que “... quer gostemos disto ou não, a sobrevivência é o critério final." (Skinner, 1956/1972c, p. 36). Ainda assim, há que se notar que: 1) essa conclusão pressupõe a concordância com o modelo de seleção por conseqüências; 2) de fato, quer a aceitemos ou não, quer gostemos ou não da sobrevivência das culturas enquanto valor, ela continuará sendo um critério de seleção de práticas culturais. Isso, porém, não implica que devamos aceitála, gostar dela ou adotá-la enquanto diretriz ética fundamental.

É preciso reconhecer que a ciência dos valores não pode justificar a opção ética pela sobrevivência das culturas - ou, pelo menos, não pode apresentá-la como um princípio científico. A sobrevivência das culturas, ao assumir a função de mando, tornase um princípio ético - ainda que, enquanto tal, sua existência seja um objeto de análise legítimo para uma ciência dos valores. Que esse princípio seja inspirado em uma ciência dos valores não significa que seja justificado por ela. Analisar cientificamente o comportamento ético não dá ao analista a capacidade de determinar o que, afinal, é bom ou mau - a não ser que ele adote um sistema ético particular de acordo com o qual possa realizar tal julgamento. Ele pode - e, enquanto cientista, deve determinar o que bom e mau significam para os sujeitos que analisa - e pode, inspirado por suas descobertas, apresentar e defender sua própria definição de bom e mau, dando valiosa contribuição para o debate ético. Porém, se a sobrevivência das culturas, enquanto valor fundamental da filosofia moral skinneriana, é uma prescrição, os behavioristas radicais não podem abster-se do debate ético. Descrever o terceiro nível de seleção do comportamento por conseqüências é uma atividade de cunho empírico. Prescrever a conseqüência selecionadora desse nível como meta do planejamento cultural é uma atividade de cunho filosófico - mesmo que seja inspirada por aquela descrição.

Não obstante, a sobrevivência das culturas é um valor legítimo: enriquece o debate ético e pode ser defendido e promovido. Há boas razões para isso. Enquanto valor, a sobrevivência prepara a cultura que a adota para a experimentação e a mudança. Essa é uma diferença importante em relação aos valores tradicionais. A sobrevivência é um valor plástico, que se adapta às circunstâncias - entre outros motivos, porque aponta não apenas para conseqüências reforçadoras, como ocorre com freqüência no discurso ético, mas também para sua relação com o comportamento que as precede (Skinner, 1968/1972d). A ética skinneriana, portanto, não dita padrões uniformes de comportamento. Nela, todos os valores - com exceção da própria sobrevivência das culturas são provisórios e flexíveis: devem ser continuamente julgados de acordo com sua contribuição para o valor básico do sistema. Assim, práticas culturais com valor de sobrevivência em certos contextos históricos, geográficos e sociais podem ser prejudiciais em outros - e, portanto, práticas culturais devem ser continuamente avaliadas de acordo com este critério. As contingências que determinam o que será ou não bom para uma cultura mudam com o passar do tempo. Assim, em determinado momento da história de uma cultura, certo conjunto de valores será o mais adequado para promover sua sobrevivência; em um momento posterior, outro conjunto de valores - talvez 
bastante diverso do anterior - poderá mostrar-se mais eficiente. O grande diferencial da ética skinneriana encontrase, exatamente, em sua maleabilidade; ela não oferece um conjunto imutável de regras, e não se baseia na autoridade. A ética skinneriana é uma ética da experimentação: abre as portas para a criatividade e a variabilidade. As "melhores" práticas culturais não existem. Podemos e devemos experimentar as mais diferentes práticas, revisando-as, modificando-as ou substituindo-as de acordo com seus possíveis efeitos sobre o fortalecimento das culturas - e aumentando, assim, a possibilidade de que boas práticas sejam selecionadas.

\section{O Sistema Ético Skinneriano e a Prática dos Analistas do Comportamento}

Se o sistema ético do behaviorismo radical apresenta sentenças prescritivas, isso significa que uma tecnologia do comportamento guiada por esta filosofia possui certos objetivos éticos - ou, em outras palavras, que o comportamento dos analistas do comportamento deveria ser reforçado por certas conseqüências específicas. Essas conseqüências traduzem-se no comportamento daqueles que são alvo da intervenção do analista: a tecnologia do comportamento só será eticamente boa se os comportamentos que produz (ou suprime) contribuírem para a sobrevivência da cultura à qual pertence o indivíduo que se comporta.

A filosofia moral de Skinner faz-se acompanhar de uma ambiciosa filosofia política - isto é, de um projeto de ação para a concretização de um ideal ético. Quer subscreva ou não às pretensões utópicas de Skinner, o analista do comportamento é, sem dúvida, um agente político, no sentido de que suas atividades profissionais possuem conseqüências éticas e políticas. Entretanto, é preciso considerar atentamente o fato de que as pessoas e grupos sobre os quais incide a tecnologia comportamental detém éticas particulares, potencialmente opostas à ética skinneriana. Essas éticas, é claro, raramente apresentam-se na forma de filosofias. A ética de um indivíduo ou de uma comunidade revelase em suas práticas e nas suas conseqüências. Dadas essas considerações, como deveria agir o analista do comportamento, enquanto profissional eticamente orientado, em sua interação com determinadas populações a fim de modificar operantes e práticas culturais?

Primeiramente, é necessário adquirir conhecimento sobre os detalhes de cada uma das diversas situações às quais aplica-se a intervenção comportamental (Skinner, 1974, 1977 / 1978b), visto que “... nenhum curso de ação deve ser exclusivamente ditado pela experiência científica ... A experiência formalizada da ciência, somada à experiência prática do indivíduo em um conjunto complexo de circunstâncias, oferece a melhor base para a ação efetiva." (Skinner, 1953/1965, p. 436). O conhecimento proporcionado pela experiência prática do indivíduo é, portanto, diferente do conhecimento científico; é um conhecimento que o cientista, em princípio, não possui. No entanto, esse conhecimento é absolutamente indispensável para a efetiva aplicação da tecnologia comportamental. É, portanto, um conhecimento que deve conjugar-se ao conhecimento científico. A fim de utilizar-se desse conhecimento, o cientista pode lançar mão de duas estratégias. A primeira é travar contato pessoalmente com a situação sobre a qual pretende intervir, "imergindo" nas contingências que a caracterizam. Embora essa seja uma estratégia freqüentemente necessária, dificilmente será suficiente. O cientista jamais terá condições de adquirir o mesmo grau de conhecimento do qual dispõem aqueles que convivem sob as contingências investigadas. A segunda alternativa aponta para a colaboração entre os detentores desse conhecimento empírico e os analistas do comportamento.

Certamente, é uma tarefa complexa harmonizar as exigências de uma ciência aplicada comprometida com o rigor experimental com as de uma ética de intervenção comunitária que enfatize a necessidade de práticas colaborativas. Porém, a reflexão sobre o assunto é necessária, e já está em andamento (Fawcett, 1991; Jacobs, 1991; Jason \& Crawford, 1991; Miller, 1991; Sherman \& Sheldon, 1991; Winett, 1991). A psicologia comunitária apresenta, tradicionalmente, preocupações dessa espécie, promovendo reflexões instigantes sobre as relações entre psicólogos, seus clientes e as instituições que apóiam e legitimam seu trabalho (DeSouza, 1996, 1998; Freitas, 1998). A incorporação dos valores da psicologia comunitária à análise aplicada do comportamento aponta para a construção de relações colaborativas, nas quais os objetivos, intervenções e resultados sejam continuamente avaliados não apenas pelo analista, mas também pela comunidade junto à qual atua (Fawcett, 1991). Trata-se, portanto, de relações que envolvem negociação de valores. Em certo sentido, esse é um tipo de relação idealizada, pois conflitos e imprevistos seguramente ocorrerão - e, neste caso, algumas perguntas fazem-se pertinentes:

Como, de fato, são decididas as prioridades? Qual é o processo? Como se alcança consenso quando os pesquisadores e os representantes da comunidade discordam? ... Embora nós reconheçamos que, enquanto "experts", não temos todas as respostas, alguns de nós não acreditam que os representantes das comunidades são sempre inerentemente sensatos [wise], e que seguirão o caminho socialmente mais válido. Nesse caso, deixamos a comunidade ou seguimos o que pode ser um caminho socialmente menos válido? (Winett, 1991, p. 637)

Adaptando esses questionamentos à discussão que empreendemos até o momento, podemos perguntar: dado que $\mathrm{o}$ analista do comportamento busca promover um valor fundamental - a sobrevivência das culturas -, e dado que seus clientes não partilharão, necessariamente, do mesmo valor, ou de valores que se adaptem a ele, qual o caminho a seguir? Uma das possibilidades seria sugerir que o analista do comportamento sabe, de antemão, o que é bom para seus clientes $-e$, sendo assim, poderia ignorar suas opiniões 
e empreender a tarefa a que se propõe de acordo com seus próprios valores. Esse padrão não é familiar em níveis mais amplos de controle cultural? Experimentemos substituir, naquela frase, analista do comportamento por governantes e clientes por governados: o que temos, então? Nesse nível de planejamento, Skinner afirma, repetidamente, que práticas culturais não podem ser impostas - pois, neste caso, não seriam as práticas certas (Skinner, 1986/1987a, 1987b).

Para fornecer outro exemplo desse padrão unilateral de decisão, podemos, ao invés de supor uma ampliação no número de clientes envolvidos, avaliar o tradicional exemplo da situação clínica, que envolve, usualmente, um único cliente. O que ocorreria se um terapeuta ignorasse as queixas e desejos de seu cliente, definindo isoladamente os objetivos da terapia? Em casos excepcionais, é possível imaginar que o cliente submeter-se-ia passivamente à intervenção do expert, porém, é mais plausível supor que haja algum tipo de reação - sobretudo se os objetivos do terapeuta contrapõem-se aos do cliente.

Em ambos os casos trata-se de apontar para a possibilidade de contracontrole - que também pode ser evitado através de práticas colaborativas (Holland, 1978; Wolf, 1978). Tais práticas podem favorecer a construção de relações equilibradas entre os analistas do comportamento e os sujeitos de sua intervenção. Não seria recomendável, por certo, romantizar uma entidade abstrata (o "povo", ou as "classes populares"), atribuindo-lhe uma superioridade ética inerente pelo fato de ser oprimida ou explorada. De certa forma, todos sabem o que é "melhor" para si - no sentido de estarem em posição privilegiada para apontar o que thes reforça o comportamento, ainda que nem sempre o façam acuradamente. Mas se as pessoas - indivíduos, comunidades ou povos - soubessem naturalmente qual é o caminho socialmente mais válido, a promoção de uma ética de sobrevivência cultural seria desnecessária. A análise do comportamento deve reconhecer e respeitar valores alheios - mas não precisa, em nome disso, abrir mão de promover seus próprios valores.

Por outro lado, conforme destacamos, os membros das comunidades nas quais intervém o analista do comportamento possuem, de fato, um tipo de conhecimento prático indispensável a uma aplicação equilibrada da tecnologia comportamental. É esse conhecimento que possibilita a tais membros avaliar a adequação ética dos objetivos, métodos e resultados da intervenção do analista: as pessoas sabem o que é "bom" para si mesmas, dadas as circunstâncias em que vivem - e, neste sentido, sua avaliação nunca estará errada. Essa avaliação não pode ser feita pelo cientista, simplesmente porque os pontos de vista - isto é, os valores, ou as circunstâncias - de acordo com os quais é realizada são outros: diferentes contingências, diferentes éticas. A avaliação ética por parte do cientista é certamente necessária, mas precisa ser conjugada à avaliação leiga.
É possível que o sistema ético do behaviorismo radical não seja o melhor (o que, obviamente, é impossível determinar), mas o fato é que os behavioristas radicais possuem um sistema ético. Se não querem abrir mão dele ao aplicar a tecnologia comportamental, devem buscar o diálogo entre esse sistema e os "sistemas" leigos. Talvez não seja tão difícil, afinal, harmonizá-los. Dado um valor fundamental bastante genérico - a sobrevivência das culturas - e considerando as possibilidades de sua aplicação a comunidades inseridas em ambientes culturais complexos, é mesmo possível que diversos analistas do comportamento apresentem diferentes diagnósticos sobre o caminho socialmente mais válido diante de situações particulares. Embora isso possa causar algum desconforto, é necessário saber conviver com a plasticidade da sobrevivência das culturas enquanto valor básico:

Não temos razão para supor que qualquer prática cultural esteja sempre certa ou errada de acordo com algum princípio ou valor independente das circunstâncias, ou que qualquer um possa, a qualquer momento, fazer uma avaliação absoluta de seu valor de sobrevivência. Conquanto isso seja reconhecido, estaremos menos inclinados a lançar mão de respostas fixas para escapar da indecisão ... (Skinner, 1953/ 1965, p. 436)

Isso amplia as possibilidades de conciliação entre os valores do analista do comportamento e os valores leigos. Diversos valores secundários podem promover a sobrevivência das culturas, subordinando-se a ela - e é bastante provável que os representantes das comunidades partilhem de alguns destes valores. Denominamos valores secundários da ética skinneriana aqueles que, de acordo com Skinner, provavelmente, contribuem para a sobrevivência das culturas: felicidade (1955-1956/1972b, 1956/1972c, 1971), saúde(1955-1956/1972b, 1956/1972c, 1971), segurança (1956/1972c, 1971), produtividade (1955-1956/1972b, 1956/1972c, 1971), educação (1955-1956/1972b, 1971), criatividade (1956/1972c), experimentação (1971), amor (1955-1956/1972b), cooperação e apoio mútuo (1972/1978a), preservação do meio ambiente (1971, 1987b), entre outros. A denominação "valores secundários", contudo, não ocorre no texto skinneriano.

Note-se que, enquanto valor fundamental, a sobrevivência das culturas remete a valores secundários praticamente leigos, de "senso comum": felicidade, saúde, segurança, educação, produtividade, amor, cooperação-não é o que todos queremos (ou ao menos a maioria de nós)? Trata-se apenas de assegurar que tais valores ajustem-se às prováveis exigências impostas pelo futuro às culturas. Assim, o analista do comportamento não se vê obrigado a confrontar um valor monolítico aos valores comunitários. Deve apenas certificar-se de que seu valor ético fundamental seja promovido através dos valores secundários defendidos pelas comunidades. Como existem diversas formas 
pelas quais promover a sobrevivência das culturas - e como, mesmo nos domínios de certo valor secundário, nenhum curso de ação é certo a priori-, o analista encontra grande mobilidade na negociação de valores.

Os valores secundários da ética skinneriana podem integrar uma plataforma inicial de ação e reflexão para os planejadores culturais cuja ética oriente-se em função da sobrevivência das culturas. Entretanto, é preciso sublinhar, novamente, um ponto de vital importância: os valores secundários não devem ser perseguidos como fins em si mesmos; devem, pelo contrário, estar sempre a serviço de um valor fundamental - a sobrevivência das culturas. Todos os valores secundários envolvem a produção de bens pessoais ou bens dos outros - isto é, de reforçadores para nosso comportamento ou para o comportamento daqueles com quem convivemos. Porém, interessa fundamentalmente ao planejador cultural saber em que medida as práticas que traduzem tais valores contribuem para o fortalecimento da cultura em questão. Valores secundários devem estar continuamente sujeitos a revisão, modificação ou substituição de acordo com esse critério.

Há, certamente, um preço a pagar por sustentar um sistema ético cujo valor fundamental não se presta facilmente à aferição. Ao mesmo tempo em que permite mobilidade experimentação, a sobrevivência das culturas produz também dúvida e indecisão, tanto para o analista do comportamento como para seus críticos. Graham (2002, p. 7), por exemplo, sumariza as objeções à "visão de Skinner da sociedade humana ideal.” A proposta de Skinner sobre "... qual é o melhor modo social de existência para um ser humano" é “... muito geral eincompleta." Os valores secundários apontados por Skinner "... dificilmente são a base detalhada de um sistema social.” Skinner não oferece “... sugestões para como melhor resolver disputas sobre maneiras de viver alternativas que são prima facie consistentes com princípios behavioristas." Além disso, “... dá pouca atenção, ou não considera seriamente, o problema geral crucial da resolução de conflitos interpessoais e o papel de arranjos institucionais em resolver conflitos."

O erro, é claro, é esperar que Skinner forneça todas as respostas, quando ele mesmo reconhece que ninguém as têm prontas (Skinner, 1953/1965, 1974, 1977/1978b). A insistência sobre a descrição antecipada de detalhes explica-se, em parte, pela incompreensão em relação à necessidade de avaliação contínua (e conseqüente adaptação) das práticas culturais de acordo com a projeção de sua possível influência sobre o destino das culturas. Note-se, no entanto, que Skinner condena, em outros sistemas éticos e políticos, a mesma generalidade da qual padece seu valor fundamental (1968/1972d).

Nem por isso a preocupação com o tema torna-se ilegítima. Para os analistas do comportamento, em especial, a questão é pungente, visto que o planejamento e modificação de práticas culturais constitui seu próprio ofício. Assim, se a análise do comportamento é sustentada por uma filosofia-o behaviorismo radical - que inclui um sistema ético, espera-se que os analistas busquem neste sistema as diretrizes para suas intervenções. Além disso, espera-se do analista que, como profissional e cidadão, esteja apto a pronunciar-se também sobre questões que, mesmo que não lhe digam respeito diretamente, sejam passíveis de intervenção através da tecnologia do comportamento. O que dizer, por exemplo, sobre práticas como o aborto ou a pena de morte?; ou sobre os problemas relativos à segurança pública?; ou sobre os freqüentes conflitos entre o poder coercivo do Estado e as chamadas "liberdades individuais"?; ou sobre as várias questões atualmente impostas no campo da bioética?; e sobre tantas outras questões legais, éticas e políticas que emergem no cotidiano das culturas? É pouco provável que o discurso dos behavioristas radicais sobre tais temas - sobre quaisquer temas que envolvam dilemas éticos e políticos - apresente-se definido, coeso, unificado. Cabe, por outro lado, perguntar: é essa unificação o que desejamos - em detrimento da variabilidade inerente ao debate ético e da ampla gama de possibilidades que se abre a uma prática norteada pela sobrevivência das culturas?

Talvez a principal "deficiência" do sistema ético skinneriano - isto é, sua generalidade, sua plasticidade - seja seu maior trunfo. A variabilidade, é claro, não deve ser considerada um fim em si mesma. Seu valor está em aumentar as possibilidades de seleção de práticas que contribuam para a preservação das culturas - mas este papel seletivo cabe às circunstâncias futuras, cuja configuração podemos apenas tentar antever e, na medida do possível, influenciar. No presente, cabe-nos produzir aqueles operantes que, de acordo com nosso mais cuidadoso julgamento, possuam amplas possibilidades de contribuir para o futuro que almejamos.

\section{Conclusão}

O sistema ético skinneriano é composto por uma ciência dos valores e por uma filosofia moral. Apoiado no modelo de seleção por conseqüências, esse sistema apresenta tanto sentenças descritivas, ou tactos - através das quais aponta as variáveis seletivas que controlam o comportamento ético - quanto sentenças prescritivas, ou mandos - através das quais destaca e promove a sobrevivência das culturas enquanto objetivo ético fundamental. Por serinspirada - mas não justificada-pelo modelo de seleção por conseqüências, a sobrevivência das culturas não constitui um valor naturalmente "verdadeiro". Esse valor pode, portanto, ser legitimamente questionado e debatido, mesmo pelos próprios behavioristas radicais - ainda que haja bons argumentos para defendê-lo.

Dada a presença de sentenças prescritivas (mandos), no sistema ético de Skinner, uma tecnologia do comportamento orientada pela filosofia deste autor deve buscar cumprir certos objetivos éticos. Há que se considerar, porém, que aqueles que são alvo da intervenção tecnológica do analista apresentam éticas particulares, potencialmente opostas à do sistema ético skinneriano. Assim, a fim de evitar o surgimento de contracontrole, o analista deve harmonizar suas próprias 
exigências éticas àquelas das comunidades com as quais interage, através de práticas colaborativas. Os valores secundários - apontados no texto skinneriano por sua suposta capacidade de contribuir para a sobrevivência das culturas podem ser utilizados para nortear a consecução desse objetivo, pois coadunam-se com valores freqüentemente defendidos por tais comunidades. Mesmo a especificação dos valores secundários, porém, não exime o sistema ético skinneriano de certa generalidade, pois há diversas formas plausíveis de traduzir estes valores em práticas que contribuam para a sobrevivência das culturas. Essa mesma característica, porém, confere flexibilidade ao processo de harmonização entre os valores do analista e os valores daqueles sobre os quais incide sua intervenção.

O discurso ético dos analistas do comportamento exibe, provavelmente, estas mesmas qualidades: generalidade e flexibilidade. Ainda que a segunda característica confira a esse discurso uma desejável variabilidade, a primeira cria dificuldades para que os analistas do comportamento apresentem um mínimo de coesão ética diante de temas específicos. Essa coesão poderia, contudo, potencializar a união de esforços em torno de objetivos éticos comuns e a mobilização política em prol destes objetivos.

\section{Referências}

Desouza, E. (1996). Psicologia comunitária nos Estados Unidos e na América Latina: Implicações para o Brasil. Psicologia: Reflexão e Crítica, 9, 5-19.

Desouza, E. (1998). Comportamento humano numa vila global: Uma perspectiva pós-moderna (construtiva) sobre psicologia comunitária do Terceiro Mundo. Psicologia: Reflexão e Crítica, 11, 147-160.

Fawcett, S. B. (1991). Some values guiding community research and action. Journal of Applied Behavior Analysis, 24, 621-636.

Freitas, M. F. Q. (1998). Inserção na comunidade e análise de necessidades: Reflexões sobre a prática do psicólogo. Psicologia: Reflexão e Crítica, 11, 175-189.

Graham, G. (2002). Behaviorism. Stanford Encyclopedia of Philosophy. Retirado em feveiro, 2003, do Stanford Encyclopedia of Philosophy World Wide Web site: http://plato.stanford.edu/entries/behaviorism

Holland, J. G. (1978). Behaviorism: Part of the problem or part of the solution? Journal of Applied Behavior Analysis, 11, 163-174.

Jacobs, H. E. (1991). Ya shoulda, oughta, wanna, or, laws of behavior and behavioral community research. Journal of Applied Behavior Analysis, 24, 641-644.

Jason, L. A. \& Crawford, I. (1991). Toward a kinder, gentler, and more effective behavioral approach in community settings. Journal of Applied Behavior Analysis, 24, 649-651.
Lewontin, R. (2002). A tripla bélice: Gene, organismo e ambiente (J. Viegas Filho, Trad.). São Paulo: Companhia das Letras. (Original publicado em 1998)

Miller, L. K. (1991). Avoiding the countercontrol of applied behavior analysis. Journal of Applied Behavior Analysis, 24, 645-647.

Sherman, J. A. \& Sheldon, J. B. (1991). Values for community research and action: Do we agree where they guide us? Journal of Applied Behavior Analysis, 24, 653655.

Skinner, B. F. (1957). Verbal behavior: New York: Appleton-Century-Crofts.

Skinner, B. F. (1965). Science and buman behavior. New York: Macmillan. (Original publicado em 1953)

Skinner, B. F. (1971). Beyond freedom and dignity. New York: Alfred A. Knopf.

Skinner, B. F. (1972a). The control of human behavior (abstract). Em B. F. Skinner (Org.), Cumulative record: A selection of papers (pp. 19-24). New York: AppletonCentury-Crofts. (Original publicado em 1955)

Skinner, B. F. (1972b). Freedom and the control of men. Em B. F. Skinner (Org.), Cumulative record: A selection of papers (pp. 3-18). New York: Appleton-CenturyCrofts. (Original publicado em 1955-1956)

Skinner, B. F. (1972c). Some issues concerning the control of human behavior. Em B. F. Skinner (Org.), Cumulative record: A selection of papers (pp. 25-38). New York: Appleton-Century-Crofts. (Original publicado em 1956)

Skinner, B. F. (1972d). The design of experimental communities. Em B. F. Skinner (Org.), Cumulative record: A selection of papers (pp. 58-65). New York: AppletonCentury-Crofts. (Original publicado em 1968)

Skinner, B. F. (1974). About behaviorism. New York: Alfred A. Knopf.

Skinner, B. F. (1978a). Freedom and dignity revisited. Em B. F. Skinner (Org.), Reflections on behaviorism and society (pp. 195-198). Englewood Cliffs, NJ: PrenticeHall. (Original publicado em 1972)

Skinner, B. F. (1978b). Human behavior and democracy. Em B. F. Skinner (Org.), Reflections on behaviorism and society (pp. 3-15). Englewood Cliffs, NJ: PrenticeHall. (Original publicado em 1977)

Skinner, B. F. (1984). Selection by consequences. Em A. C. Catania \& S. Harnad (Orgs.), Canonical papers of B. F. Skinner (pp. 477-481). The Behavioral and Brain Sciences, 7, 473-724. (Original publicado em 1981)

Skinner, B. F. (1987a). What is wrong with daily life in the western world? Em B. F. Skinner (Org.), Upon further reflection (pp. 15-31). Englewood Cliffs, NJ: PrenticeHall. (Original publicado em 1986)

Skinner, B. F. (1987b). Why we are not acting to save the world. Em B. F. Skinner (Org.), Upon further reflection (pp. 1-14). Englewood Cliffs, NJ: Prentice-Hall.

Winett, R. A. (1991). Caveats on values guiding community research and action. Journal of Applied Bebavior Analysis, 24, 637-639.

Wolf, M. M. (1978). Social validity: The case for subjective measurement or how applied behavior analysis is finding its heart. Journal of Applied Behavior Analysis, 11,203-214.

Sobre os autores

Alexandre Dittrich é Psicólogo pela Universidade Regional de Blumenau, Doutorando em Epistemologia da Psicologia e da Psicanálise pela Universidade Federal de São Carlos.

José Antônio Damásio Abib é Psicólogo pela Universidade de Brasília, Mestre em Psicologia e Doutor em Ciências pela Universidade de São Paulo. Pós-Doutor em Epistemologia da Psicologia na Dinamarca (1989-1991). Orientador do Programa de Doutorado em Epistemologia da Psicologia e da Psicanálise do Departamento de Filosofia e Metodologia das Ciências da Universidade Federal de São Carlos. 